\title{
Inducible left-ventricular intracavity gradient during dobutamine stress echocardiography - a condition worth noting
}

\author{
Nina Jakuš1*, Vedran Velagićc ${ }^{2}$ Dubravka Memićc ${ }^{2}$ Jadranka Šeparović Hanževački², \\ Davor Miličićc ${ }^{2}$ Maja Čikeš \\ ${ }^{1}$ University of Zagreb School of Medicine, Zagreb, Croatia \\ ${ }^{2}$ University of Zagreb School of Medicine, University Hospital Center Zagreb, Zagreb, Croatia
}

Objectives: To evaluate the incidence and left ventricular (LV) morphologic characteristics of patients developing dynamic intraventricular obstruction induced during dobutamine stress echocardiography (DSE).

Methods: We studied 77 patients (42 men - 55\%; mean age $61 \pm 12$ years) referred for standard high-dose DSE due to exertional dyspnoea or chest pain. The patients were divided into two groups - group I consisted of patients who developed a significant left-ventricular (LV) intracavitary gradient (>20 $\mathrm{mmHg}$ ) during DSE (33 patients, 45\% men, mean age $58.6 \pm 12.5$ years) and group II consisted of patients without an inducible gradient (44 patients - $61 \%$ men; mean age $62.5 \pm 10.7$ years). The intracavitary gradient was defined as a late-peaking left ventricular Doppler velocity profile exceeding basal velocity by $1 \mathrm{~m} / \mathrm{sec}$.

Results: $43 \%$ of the studied patients developed the gradient during high stages of dobutamine infusion $(>20 \mathrm{mcg} / \mathrm{kg} /$ min). Mean intracavitary gradient was $75.1 \mathrm{mmHg}$ (range $20-135 \mathrm{mmHg}$ ). Patients in group I had statistically smaller LV cavity dimensions (Table 1) but their ejection fraction and fractional shortening were greater. These measurements were done using the Teicholtz method which is based on measuring the radial function of the LV (Table 1). Hypertension was present in a larger percentage of patients in the group I compared to the group II, however not reaching statistical significance (group | 30\%, group || 18\%, $p=0.28$ ). According to patient histories somewhat more patients in the group I (27\%) experienced symptoms like dyspnoea or chest pain during dobutamine infusion than in the group II (18\%). The DSE study (Figure 1) was positive for inducible ischaemia in a significantly greater number of patients in the group II, compared to the patients developing the gradient (88\% to $12 \%)$.

Conclusion: An inducible LV intracavitary gradient occurred in a large number (43\%) of patients referred to DSE in our centre. These patients had significantly smaller LV cavity dimensions which, together with notably increased radial function, likely contributes to the development of the gradient. Higher values of LV radial function measurements are common in hypertension. Indeed, we noted a higher inci-

Table 1. Echocardiographic data of the patients of group I (developed the gradient) and group II (did not develop the gradient).

\begin{tabular}{llcc|}
\hline & Group I & Group II & p-value \\
\hline IVSd (cm) & $1.04 \pm 0.30$ & $1.04 \pm 0.27$ & 0.5 \\
LVIDd (cm) & $4.81 \pm 0.75$ & $5.38 \pm 0.92$ & 0.003 \\
LVPWd (cm) & $1.03 \pm 0.56$ & $0.99 \pm 0.23$ & 0.33 \\
LVIDs (cm) & $2.88 \pm 0.82$ & $3.57 \pm 1.12$ & 0.002 \\
EDV (Teich) $(\mathrm{mL})$ & $111.97 \pm 39.56$ & $144.30 \pm 61.94$ & 0.01 \\
ESV (Teich) $(\mathrm{mL})$ & $37.85 \pm 22.03$ & $62.59 \pm 49.66$ & 0.005 \\
EF (\%) & $66.94 \pm 15.10$ & $60.57 \pm 16.08$ & 0.04 \\
FS (\%) & $38.58 \pm 11.46$ & $33.73 \pm 10.94$ & 0.03 \\
\hline
\end{tabular}

IVSd = interventricular septal thickness at diastole, LVIDd = left ventricle internal dimension in diastole, LVPWd = left ventricular posterior wall dimensions, LVIDs = left ventricular internal dimension in systole, EDV = end-diastolic volume, ESV = end-systolic volume, Teich $=$ Teicholz, EF = ejection fraction, FS = fractional shortening, Ao Diam = aortic root diameter. 


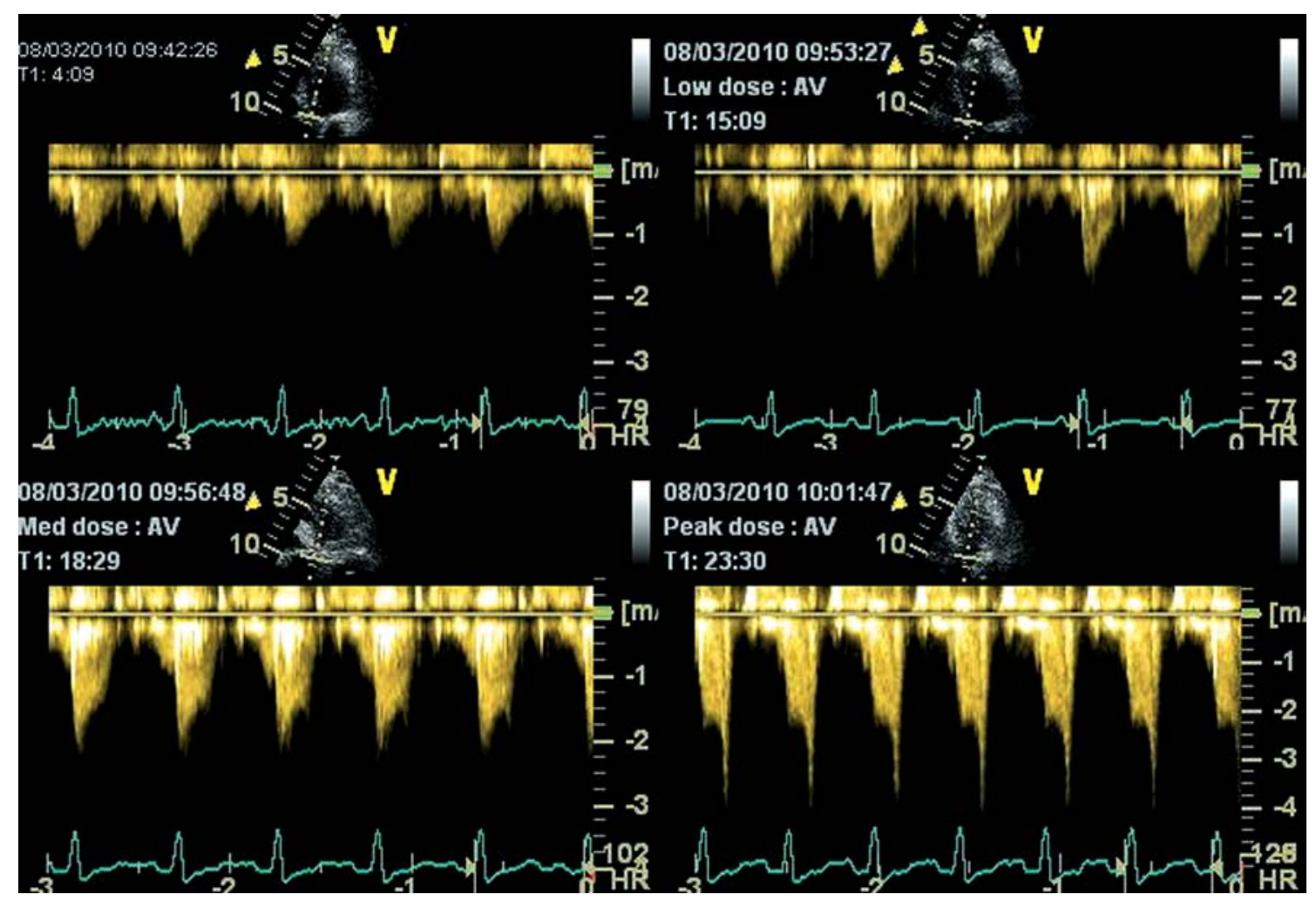

Figure 1. Continuous Doppler trace of the left ventricular outflow tract with an increasing dose of dobutamine. At maximum dose, the inducible gradient appears with the characteristic Doppler trace morphology.

dence of hypertension in the group developing the intracavitary gradient. In this group of patients, the occurrence of inducible ischaemia was significantly lower.

KEYWORDS: dobutamine stress echocardiography, intraventricular gradient, dyspnoea.

CITATION: Cardiol Croat. 2013;8(9):307-308.

\section{Received: $2^{\text {nd }}$ Aug 2013}

*Address for correspondence: Medicinski fakultet Sveučilišta u Zagrebu, Šalata 3 , Zagreb, Croatia.

Phone: +385-91-560-5795

E-mail: nina.jakush@gmail.com

\section{Literature}

1. Pellikka PA, Oh JK, Bailey KR, Nichols BA, Monahan KH, Tajik AJ. Dynamic intraventricular obstruction during dobutamine stress echocardiography. A new observation. Circulation. 1992;86(5):1429-32.

2. Barletta G, Del Bene MR, Gallini C, et al. The clinical impact of dynamic intraventricular obstruction during dobutamine stress echocardiography. Int J Cardiol. 1999;70(2):17989.

3. Henein MY, O'Sullivan C, Sutton GC, Gibson DG, Coats AJ. Stress-induced left ventricular outflow tract obstruction: a potential cause of dyspnea in the elderly. J Am Coll Cardiol. 1997;30(5):1301-7. 